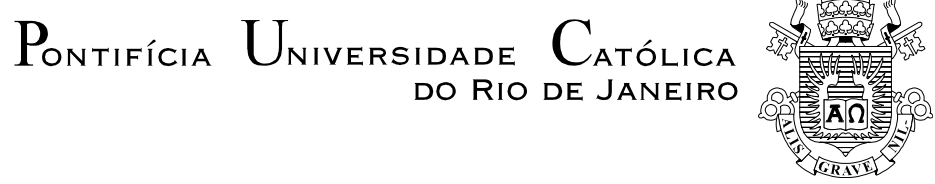

Trond Martin Augustson

\title{
VISION BASED IN-SITU CALIBRATION OF ROBOTS WITH APPLICATION IN SUBSEA INTERVENTIONS
}

\author{
M.Sc. Thesis
}

Thesis presented to obtain the M.Sc. title at the Mechanical Engineering Department at PUC-Rio.

Advisor: Marco Antonio Meggiolaro

Rio de Janeiro

September 2007 


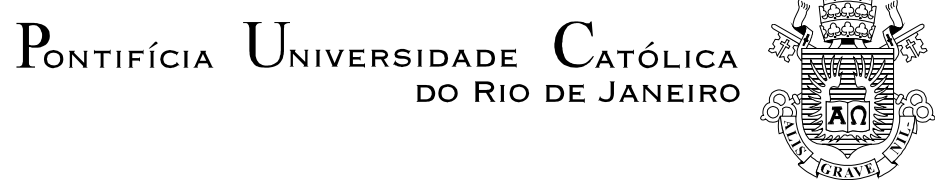

Trond Martin Augustson

\section{CALIBRAGEM VISUAL IN SITU DE MANIPULADORES ROBÓTICOS COM APLICAÇÃO EM INTERVENÇÕES SUBMARINAS}

Dissertação apresentada como requisito parcial para obtenção do grau de Mestre pelo Programa de PósGraduação em Engenharia Mecânica do Departamento de Engenharia Mecânica do Centro Técnico Científico da PUC-Rio. Aprovada pela Comissão Examinadora abaixo assinada.

Prof. Marco Antonio Meggiolaro Orientador Pontifícia Universidade Católica do Rio de Janeiro

Prof. Mauro Speranza Neto Pontifícia Universidade Católica do Rio de Janeiro

Prof. Raul Queiroz Feitosa Pontifícia Universidade Católica do Rio de Janeiro

Prof. Fernando Cesar Lizarralde Universidade Federal do Rio de Janeiro

Prof. José Eugenio Leal Coordenador Setorial do Centro

Técnico Científico - PUC-Rio

Rio de Janeiro, 3 de setembro de 2007 
All rights reserved. Any reproduction of this work without authorization from the university, the author and the advisor is prohibited.

\section{Trond Martin Augustson}

Graduated in applied physics at The University of Bergen in 1998. He has worked with seismic surveying until entering the master program at PUC-Rio in 2005.

Ficha Catalográfica 


\section{Thanks to}

- $\quad$ My advisor Marco Antonio Meggiolaro, for help and support;

- $\quad$ Professor Raul Feitosa, for the contribution on computer vision;

- $\quad$ PUC-Rio for the opportunity and the great academic environment that constitute the basis of this work;

- CENPES/PETROBRAS for the support, including the submarine camera and information on the TA-40 manipulator;

- $\quad$ My family, however distant, supporting me during my work. 


\section{Abstract}

Augustson, Trond Martin; Meggiolaro, Marco Antonio (Orientador). VISION BASED IN-SITU CALIBRATION OF ROBOTS WITH APPLICATION IN SUBSEA INTERVENTIONS. Rio de Janeiro 2007, 143p. M.Sc. Dissertation -Mechanical Engineering Department, Pontifícia Universidade Católica do Rio de Janeiro.

The majority of today's industrial robots are programmed to follow a predefined trajectory. This is sufficient when the robot is working in a fixed environment where all objects of interest are situated in a predetermined position relative to the robot base. However, if the robot's position is altered all the trajectories have to be reprogrammed for the robot to be able to perform its tasks. Another option is teleoperation, where a human operator conducts all the movements during the operation in master-slave architecture. Since any positioning errors can be visually compensated by the human operator, this configuration does not demand that the robot has a high absolute accuracy. However, the drawback is the low speed and low accuracy of the human operator scheme. The manipulator considered in this thesis is attached to a ROV (Remote Operating Vehicle) and is brought to its working environment by the ROV operator. Every time the robot is repositioned, it needs to estimate its position and orientation relative to the work environment. The ROV operates at great depths and there are few sensors which can operate at extreme depths. This is the incentive for the use of computer vision to estimate the relative position of the manipulator. Through cameras the differences between the actual and desired position of the manipulators is estimated. This information is sent to controllers to correct the pre-programmed trajectories. The manipulator movement commands are programmed off-line by a CAD system, without need even to turn on the robot, allowing for greatest speed on its validation, as well as problem solving. This work includes camera calibration and calibration of the structure of the manipulator. The increased accuracies achieved by these steps are merged to achieve in-situ calibration of the manipulator base.

\section{Key Words}

Robotics; Calibration; Computer vision; SIFT; Pattern recognition; Automation; Stereopsis 


\section{Resumo}

Augustson, Trond Martin; Meggiolaro, Marco Antonio (Advisor). CALIBRAGEM VISUAL IN SITU DE MANIPULADORES ROBÓTICOS COM APLICAÇÃO EM INTERVENÇÕES SUBMARINAS. Rio de Janeiro 2007, 143p. Dissertação de Mestrado Departamento de Engenharia Mecânica, Pontifícia Universidade Católica do Rio de Janeiro.

A maioria dos robôs industriais da atualidade são programados para seguir uma trajetória pré-definida. Isto é suficiente quando o robô está trabalhando em um ambiente imutável onde todos os objetos estão em uma posição conhecida em relação à base do manipulador. No entanto, se a posição da base do robô é alterada, todas as trajetórias precisam ser reprogramadas para que ele seja capaz de cumprir suas tarefas. Outra opção é a teleoperação, onde um operador humano conduz todos os movimento durante a operação em uma arquitetura mestre-escravo. Uma vez que qualquer erro de posicionamento pode ser visualmente compensado pelo operador humano, essa configuração não requer que o robô possua alta precisão absoluta. No entanto, a desvantagem deste enfoque é a baixa velocidade e precisão se comparado com um sistema totalmente automatizado. O manipulador considerado nesta dissertação está fixo em um ROV (Remote Operating Vehicle) e é trazido até seu ambiente de trabalho por um teleoperador. A cada vez que a base do manipulador é reposicionada, este precisa estimar sua posição e orientação relativa ao ambiente de trabalho. O ROV opera em grandes profundidades, e há poucos sensores que podem operar nestas condições adversas. Isto incentiva o uso de visão computacional para estimar a posição relativa do manipulador. A diferença entre a posição real e a desejada é estimada através do uso de câmeras submarinas. A informação é enviada aos controladores para corrigir as trajetórias préprogramadas. Os comandos de movimento do manipulador podem então ser programados off-line por um sistema de CAD, sem a necessidade de ligar o robô, permitindo rapidez na validação das trajetórias. Esse trabalho inclui a calibragem tanto da câmera quanto da estrutura do manipulador. As melhores precisões absolutas obtidas por essas metodologias são combinadas para obter calibração in-situ da base do manipulador.

\section{Palavras-Chave}

Robótica; Calibragem; Visão computacional; SIFT; Reconhecimento de padrões; Automação; Visão estéreo 


\section{Summary}

1 Introduction 20

1.1. Motivation 20

1.2. Work objectives 20

1.3. Work description $\quad 21$

1.4. Organization of the Thesis 24

2 Kinematic Modeling for Calibration of Manipulators 26

2.1. Introduction 26

2.2. Basic Concepts of Kinematics 28

2.3. The Denavit-Hartenberg Convention 29

2.4. Classic Manipulator Calibration 32

2.5. Elimination of Redundant Errors 36

2.6. Physical Interpretation of the Redundant Errors 38

2.7. Partial Measurement of End-Effector Pose 39

2.8. Inverse Kinematics 40

2.8.1. Solvability 40

2.9. Experimental Procedures $\quad 41$

3 Computer Vision $\quad 47$

3.1. Introduction $\quad 47$

3.2. Mathematic Camera Models 48

3.2.1. The Pinhole Model 48

3.2.2. Intrinsic Parameters 49

3.2.3. Extrinsic Parameters 51

3.3. Camera Calibration 52

3.3.1. Radial Distortion 56

3.3.2. Sophisticated calibration 58

3.3.3. Coordinate extraction 61

$\begin{array}{ll}\text { 3.3.4. Nonmaximum Suppression } & 61\end{array}$ 
3.3.5. K-means Line Fitting

3.4. Feature Matching 64

3.4.1. Detection of Interest Points 65

3.4.2. Elimination of Edge Responses 66

3.4.3. Accurate keypoint localization 67

3.4.4. Assigning Orientation 68

3.4.5. The Key-Point Descriptor 69

3.4.6. Invariance to orientation and illumination $\quad 70$

3.4.7. Keypoint matching 71

3.5. Triangulation 73

3.6. Stereo Vision 76

3.7. Manipulator Base Calibration 78

3.7.1. Quaternion Algebra 79

3.7.2. Estimation of the Rotation Matrix Using Quaternions 80

3.8. Elimination of Keypoint Matches using RANSAC 83

3.9. Triangulation Using the Kinematics of the Manipulator 85

4 Application to the TA-40 Manipulator 90

4.1. Introduction 90

4.2. Description of the Manipulator 90

4.3. Kinematics of the TA-40 91

4.3.1. Joints 1 and 2

4.3.2. Joints 2 and 3

4.3.3. Joints 3 and 4

4.3.4. Joints 4 and 5

4.3.5. Joints 5 and $6 \quad 94$

4.3.6. Joint $6 \quad 94$

4.3.7. Denavit-Hartenberg Parameters 94

4.4. Calibration of the TA-40 95

4.5. Inverse Kinematics 96

4.6. Orientation Error of the Manipulator 101

5 Results 108

5.1. Introduction 108 
5.2. Laboratory Experiments 108

5.2.1. Camera Calibration 110

5.2.2. Experiments with the X-Y Table 113

5.3. Calibration of an Underwater Camera 123

5.4. Position Estimation using the Underwater Camera 125

5.5. Camera Calibration performed Underwater 132

6 Conclusions and Suggestions 134

6.1. Conclusions 134

$\begin{array}{ll}\text { 6.2. Suggestions for future work } & 135\end{array}$

7 References 136

$\begin{array}{ll}\text { Appendix A } & 139\end{array}$ 


\section{List of figures}

Figure 1 - Repeatability and absolute accuracy................................. 21

Figure 2 - Coordinate systems of the manipulator .............................. 27

Figure 3 - Denavit-Hartenberg parameters [5] ................................... 30

Figure 4 -Translation and rotation with effects of errors in the i-th link [6] 32

Figure 5 - Generalized errors for the i-th link. $\varepsilon_{\mathrm{p}, \mathrm{i}}, \varepsilon_{\mathrm{s}, \mathrm{i}}, \varepsilon_{\mathrm{r}, \mathrm{i}}$ represent the rotation around the $x, y$ and $z$-axes respectively. [6] .................. 33

Figure 6 - Error compensation block diagram [6] ............................... 35

Figure 7 - Combination of translational linear errors [6]...................... 38

Figure 8 - Simplified combination of error [6] ................................... 39

Figure 9 - Finding the rotation axis of joint $2\left(Z_{1}\right)$, side view ................ 42

Figure 10 - Finding the rotation axis of joint $1\left(Z_{0}\right)$, upper view ............. 42

Figure 11 - The trajectory of the probe forms a plane that is found by a least square approximation .

Figure 12 - Angles between the laser tracker reference frame and the normal plane [12] 44

Figure 13 - Schematic representation of the pinhole model ...................48

Figure 14 - Geometry of the pinhole model [14]. 49

Figure 15 - CCD layout. (a) shows an ideal square, (b) shows that the scale in $x$ and $y$ direction can differ, (c) shows that the axes might not be perpendicular [14]. 49

Figure 16 - The modified pinhole model. [14] 50

Figure 17 - The image center is not always in the middle of the sensor since the lens normal does not intersect with the middle of the sensor panel.

Figure 18 - Transformation of world coordinates to camera coordinates. [14] 52

Figure 19 - Calibration rig 53

Figure 20 - Transformation from world coordinates to picture coordinates. [14] 
Figure 21 - Types of radial distortion.

Figure 22 - Principle of barrel distortion. The black coordinates represent the image coordinates for a camera without distortion. The violet coordinates show the distorted image coordinates.

Figure 23 - The 4 directions used in nonmaximum suppression

Figure 24 - Output of the nonmaximum suppression algorithm.

Figure 25 - Maxima and minima in the Difference-of-Gauss are compared to its 26 neighbors [3]. 66

Figure 26 - Histogram of key-point orientation [3].

Figure 27 - Keypoint calculation process. Each 4x4 element of gradients (left) is referred to as a bin. For each bin a histogram of 8 directions is calculated (right) [3] 70

Figure 28 - Distribution of relative keypoint orientation. 72

Figure 29 - Triangulation 73

Figure 30 - Stereo Triangulation. 76

Figure 31 -Initial procedure to estimate the position of the reference camera relative to the keypoints. Creating a set of 3D coordinates, ${ }^{1} p$

Figure 32 - Finding a second set of corresponding coordinates, ${ }^{2} p$

Figure 33 - TA40 and the miniature robot used as master

Figure 34 - TA-40 and coordinate systems [1]

The frame center $\mathrm{O}_{4}$ of joint 5 is located $747 \mathrm{~mm}$ along the $\mathrm{z}_{4}$ axis from $\mathrm{O}_{4}$, giving $\mathrm{d}_{4}=747$. Since the frame centers position along the common normal is zero, $a_{4}=0$. The $z_{4}$ axis is rotated $-90^{\circ}$ relative to $z_{3}$, giving $\alpha_{4}=-90^{\circ}$.

Figure 35 - A 2D interpretation of the frames $\mathrm{O}_{2}, \mathrm{O}_{3}$ and $\mathrm{O}_{4}$. Frame $\mathrm{O}_{5}$ coincides with frame $\mathrm{O}_{4}[24]$. 97

Figure 36 - Position error of end-effector after calibration 104

Figure 37 - Rotation error at the end effector after calibration. 105

Figure 38 - Position error of link 5 after calibration 106

Figure 39 - Rotation error of link 5 after calibration 107 
Figure $40-x-y$ table in the Robotics laboratory at PUC 109

Figure 41 - Calibration rig 109

Figure 42 - Edges of the calibration rig. The estimated corners are marked in red.

Figure 43 - Figure showing the edges of the image in white. The image to the left shows the initial k-mean line parameters. The image on the right shows the improved estimate after only three iterations. The estimated coordinate of the corner is marked in red. The yellow and green lines show the estimated lines.

Figure 44 - Relative movement between extracted coordinates and the projected coordinates.

Figure 45 - The robot used as reference object in the experiment

Figure 46 - Coordinate system of the $x$-y table

Figure $47-$ Method to estimate the set of coordinates, ${ }^{2} p$. The reference image is marked in yellow. The position of one of the two cameras is to be estimated relative to the reference image

Figure 48 - Triangulation to estimate the coordinate set ${ }^{1} p$ relative to the origin. The reference image is marked in yellow. The images closest to the reference image and the two cameras used to estimate the coordinate set ${ }^{2} p$ were not used.

Figure 49 - RMS position error as a function of intraocular distance using RANSAC and quaternion rotation estimation

Figure 50 - Graph showing the average RMS position error as a function of the intraocular distance after the samples with the worst error ratio had been removed.

Figure 51 - RMS position error as a function of intraocular distance using RANSAC with LMS rotation estimate.

Figure 52 - RMS position error as a function of intraocular distance using RANSAC with LMS rotation estimate and eliminating the coordinates with a high error ratio.

Figure 53 -The corrected image coordinates relative to their respective extracted image coordinates 
Figure 54 - Attachment support for the underwater camera

Figure 55 - Position accuracy as a function of the intraocular distance using all 72 coordinates and quaternion rotation estimation. .

Figure 56 - Position accuracy as a function of the intraocular distance after the coordinates with a large error ratio had been eliminated.

Figure 57 - Position error as a function of intraocular distance with the underwater camera using all 72 coordinates and LMS rotation estimation.

Figure 58 - Position accuracy as a function of the intraocular distance after the coordinates with a large error ratio had been eliminated.

Figure 59 - Underwater calibration. The green points are the corrected image coordinates and the red lines show their respective image coordinates

Figure A.1 - Coordinate systems of the TA-40. 


\section{List of Tables}

Table 1 - Denavit-Hartenberg parameters …………............................... 94

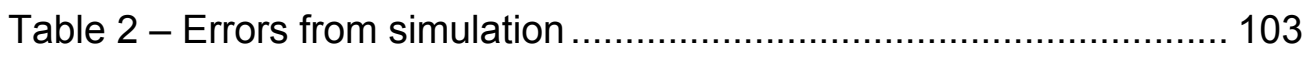

Table 3 - Camera calibration parameters........................................... 112

Table 4 - Position parameters for the experiment................................. 115

Table 5 - Position error as a function of intraocular distance using

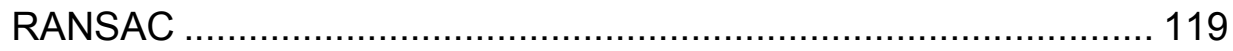

Table 6 - Position error as a function of intraocular distance using RANSAC and error ratio elimination.

Table 7 - Position error as a function of intraocular distance using RANSAC together with the least mean square estimated rotation matrix.

Table 8 - Position error as a function of intraocular distance using RANSAC together with the least mean square estimated rotation matrix and eliminating the coordinates with error ratio.

Table 9 -Calibration parameters for the underwater camera in air, where $s_{u}$ is the aspect ratio, $\mathrm{f}$ is the focal length, $k_{1}$ and $k_{2}$ are the radial distortion coefficients, $T_{1}$ and $T_{2}$ are the tangential distortion coefficients and $\left(u_{0}, v_{0}\right)$ denotes coordinates of the image center.

Table 10 - Position parameters for the experiment with the underwater camera.

Table 11 - Position error as a function of intraocular distance using the underwater camera, all 72 coordinates, and quaternion rotation estimation.

Table 12 - Position accuracy as a function of the intraocular distance after the coordinates with a large error ratio had been eliminated.

Table 13 - Position error as a function of intraocular distance using the underwater camera using all 72 coordinates and LMS rotation estimation. 
Table 14 - Position accuracy as a function of the intraocular distance after the coordinates with a large error ratio had been eliminated..

Table 15 - Calibration parameters for the underwater camera in air, where $\mathrm{s}_{\mathrm{u}}$ is the aspect ratio, $f$ is the focal length, $\mathrm{k}_{1}$ and $\mathrm{k}_{2}$ are the radial distortion coefficients, $T_{1}$ and $T_{2}$ are the tangential distortion coefficients and $\left(u_{0}, v_{0}\right)$ denotes coordinates of the image center. 


\section{List of Variables}

$\mathrm{A}_{\mathrm{q}}$ - Observation matrix used in quaternion rotation estimation

$\mathrm{C}_{\mathrm{a}}$ - Observation matrix for plane estimation

$C_{a}-$ Observation matrix for arc coordinates projected onto the estimated plane

$\mathrm{C}_{\mathrm{t}}$ - Observation matrix for translated coordinates used to estimate circle parameters

$\mathrm{G}_{\mathrm{e}}$ - Non singular Identification matrix where the redundant errors have been eliminated.

$T_{n}^{0}$ - homogeneous matrix $4 \times 4$ that describes the orientation and position of the manipulator end-effector relative to its base as a function of the angles of the links $\theta_{\mathrm{n}}$ and the generalized errors $\varepsilon$.

$a_{i}$ - Denavit-Hartenberg parameter: length of the common normal between two adjacent links

$a-$ quaternion vector

$a_{0}, a_{1}, a_{2}, a_{3}$ - quaternion vector components of $a$.

$a_{p}$ - parameter for an estimated $3 \mathrm{D}$ plane

$a_{l}$ - line parameter used to estimate a line through least square approximation

$b$ - quaternion vector

$b_{0}, b_{1}, b_{2}, b_{3}$ - quaternion vector components

$b_{t}$ - parameter used to estimate a circle from translated arc parameters

$b_{q}-$ vector used in quaternion rotation estimation

$b_{l}$ - line parameter used to estimate a line through least square approximation

$b_{p}$ - parameter for an estimated $3 \mathrm{D}$ plane

$c_{l}$ - line parameter used to estimate a line through least square approximation

$c_{p}$ - parameter for an estimated 3D plane

$c_{r}$ - estimated radius of projected circle

$\mathrm{d}_{\mathrm{mnop}}$ - variable used in deduction of triangulation principles

$d_{p}$ - parameter for an estimated 3D plane 
$d_{i}$ - Denavit-Hartenberg parameter: distance between the origin $O_{i-1}$ and $H_{i}$

$\mathrm{d}_{\text {int }}-$ Intraocular distance between two camera centers

$d_{n}$ - distance limit that denotes the maximum allowed distance from the nearest corresponding coordinate

$d_{r, i}-$ a coordinates' distance from the cluster center ${ }_{R}^{1} p$

$e_{0}$ - matrix containing the edge angle of an image

$\mathrm{i}$ - complex quaternion unit vector

$\mathrm{j}$ - complex quaternion unit vector

$\mathrm{k}$ - complex quaternion unit vector

$\mathbf{k}$ - quaternion rotation axis given by $\mathbf{k}=[\mathrm{i} \mathrm{j} \mathrm{k}]$

$n_{p}$ - normal vector for estimated plane

$\hat{p}$ - coordinate in the normalized in the normalized image plane

${ }^{1} p-3 \mathrm{D}$ coordinate set relative to the origin

${ }^{2} p$ - 3D coordinate set corresponding to ${ }^{1} p$ with a different reference frame

${ }_{R}^{1} p$ - translated coordinate set, used in RANSAC algorithm

${ }_{R}^{\tilde{1}} p$ - estimated center of the translated coordinate set ${ }_{R}^{1} p$

$q$ - quaternion vector

$q_{0}, q_{1}, q_{2}, q_{3}$ - quaternion vector components of $\mathrm{q}$

$r_{e, i}$ - error ratio of a coordinate, denoting its position error relative to its distance

from the center of the cluster.

$r_{\lim }-$ error ratio limit, denoting the accepted error ratio $r_{e, i}$

$r_{r}$ - estimated radius of projected circle

$\hat{u}$ - normalized $\mathrm{x}$-coordinate of an image relative to the image center

$\hat{v}$ - normalized y-coordinate of an image relative to the image center

$u$ - image $\mathrm{x}$-coordinate corrected for radial distortion

$v$

$v$ - image y-coordinate corrected for radial distortion

$u_{t}$ - output vector from least square estimate of a circle

$v_{p}$ - least square vector estimated by a lest square of $\mathrm{C}_{\mathrm{a}}$

$x_{a}-\mathrm{x}$ coordinate of an arc projected onto plane 
$x_{i}$ - coordinate of joint $\mathrm{i}$ in the Denavit-Hartenberg notation

$x_{q}$ - substitution parameter used in quaternion deduction

$x_{r}$ - estimated $\mathrm{x}$-coordinate of circle center

$x_{t}$ - translated $\mathrm{x}$-coordinate used to estimate circle parameters

$x_{t r i}$ - coordinate defining a point used in triangulation

$y_{a}-\mathrm{y}$-coordinate of an arc projected onto plane

$y_{q}-$ substitution parameter used in quaternion deduction

$y_{r}$ - estimated y-coordinate of circle center

$y_{t}-$ translated $\mathrm{x}$-coordinate used to estimate circle parameters

$y_{t r i}$-coordinate defining a point used in triangulation

$y_{i}$ - coordinate of joint $\mathrm{i}$ in the Denavit-Hartenberg notation

$z_{i}$ - coordinate of joint $i$ in the Denavit-Hartenberg notation

$z_{\text {tri }}$-coordinate defining a point used in triangulation

$C_{a}$ - observation matrix of arc coordinates relative to the laser tracker

$C_{a}^{\prime}-$ matrix containing the projected coordinates of $C_{a}$

$G$ - matrix containing the edge magnitude of an image

$G_{x}$ - matrix containing the edge magnitude in x direction of an image

$G_{y}$ - matrix containing the edge magnitude in y direction of an image

$\mathrm{S}_{\mathrm{x}}$ - Sobel filter mask for detecting edges in $\mathrm{x}$ direction

$\mathrm{S}_{\mathrm{y}}$ - Sobel filter mask for detecting edges in y direction

$L_{o}$ - observation matrix for camera calibration

$M$ - projection matrix of the pin hole camera

$M_{v}$ - projection matrix in vector form

${ }^{\mathrm{c}} \mathrm{O}$ - camera reference frame

${ }^{\mathrm{w}} \mathrm{O}$ - world reference frame

${ }^{c} P$ - coordinate relative to the camera reference frame

${ }^{w} P$ - coordinate relative to the world reference frame

$Q$ - skew matrix used to calculate vector product

$R$ - rotation matrix defining the relative rotation between two views

$\Delta \mathrm{X}$ - difference between desired position of the manipulator end-effector and the actual position. 
$\Delta X_{t}$-matrix containing differences between desired position of the manipulator end-effector and the true measured position.

$\boldsymbol{J}_{\boldsymbol{t}}$ - The matrix $6 m \times 6(n+1)$ formed by $m$ Identification Jacobians, called the Total Identification matrix

$\alpha-$ magnification factor in $\mathrm{x}$ direction for the pin hole model [pixels]

$\beta-$ magnification factor in y direction for the pin hole model [pixels]

$\alpha_{i}$ - Denavit-Hartenberg parameter: the angle between the joint axes in the right hand sense.

$\hat{\varepsilon}$ - vector containing the estimated generalized errors

$\varepsilon$ - vector where the redundant errors are incorporated in the non redundant errors

$\varepsilon_{x, i}$ - Generalized error of joint $i$ along $x$-axis

$\varepsilon_{y, i}$ - Generalized error of joint $i$ along $y$-axis

$\varepsilon_{z, i}$ - Generalized error of joint $i$ along $z$-axis

$\varepsilon_{p, i}$ - Generalized rotational error of joint $i$ around $\mathrm{x}$-axis

$\varepsilon_{s, i}$ - Generalized rotational error of joint $i$ around $y$-axis

$\varepsilon_{r, i}$ - Generalized rotational error of joint $i$ around $z$-axis

$\gamma_{1}, \gamma_{2}$ - multiplication factors that determines at what coordinate the closest mutual point is found for two lines in 3D

$\theta_{i}$ - Denavit-Hartenberg parameter: the angle between the $x_{i-1}$ axis and the common normal $H_{i} O_{i}$ measured along the $z$-azis

$\theta_{p, x}$ - estimated angle around the $x$-axis, between the normal plane and the reference frame.

$\theta_{p, y}$ - estimated angle around the $y$-axis, between the normal plane and the reference frame.

$\theta_{\mathrm{q}}-$ quaternion rotation angle

$\theta_{x_{0}}$ - camera bias angle around $x$-axis

$\theta_{y_{0}}$ - camera bias angle around $y$-axis

$\theta_{z_{0}}$ - camera bias angle around z-axis

$\zeta$ - substitution variable used in estimation of quaternion rotation angle

$\rho$ - substitution variable used in estimation of quaternion rotation angle 